\title{
Molecular basis of PRC1 targeting to Polycomb response elements by PhoRC
}

\author{
Felice Frey, ${ }_{1}^{1}$ Thomas Sheahan, ${ }^{1}$ Katja Finkl, ${ }^{1}$ Gabriele Stoehr, ${ }^{2}$ Matthias Mann, ${ }^{2}$ Christian Benda, ${ }^{3}$ \\ and Jürg Müller ${ }^{1}$ \\ ${ }^{1}$ Laboratory of Chromatin Biology, Max Planck Institute of Biochemistry, 82152 Martinsried, Germany; ${ }^{2}$ Department of \\ Proteomics and Signal Transduction, Max Planck Institute of Biochemistry, 82152 Martinsried, Germany; ${ }^{3}$ Department of \\ Structural Cell Biology, Max Planck Institute of Biochemistry, 82152 Martinsried, Germany
}

Polycomb group (PcG) protein complexes repress transcription by modifying target gene chromatin. In Drosophila, this repression requires association of PcG protein complexes with cis-regulatory Polycomb response elements (PREs), but the interactions permitting formation of these assemblies are poorly understood. We show that the Sfmbt subunit of the DNA-binding Pho-repressive complex (PhoRC) and the Scm subunit of the canonical Polycombrepressive complex 1 (PRC1) directly bind each other through their SAM domains. The 1.9 A crystal structure of the Scm-SAM:Sfmbt-SAM complex reveals the recognition mechanism and shows that Sfmbt-SAM lacks the polymerization capacity of the SAM domains of Scm and its PRC1 partner subunit, Ph. Functional analyses in Drosophila demonstrate that Sfmbt-SAM and Scm-SAM are essential for repression and that PhoRC DNA binding is critical to initiate PRC1 association with PREs. Together, this suggests that PRE-tethered Sfmbt-SAM nucleates PRC1 recruitment and that Scm-SAM/Ph-SAM-mediated polymerization then results in the formation of PRC1compacted chromatin.

[Keywords: PRC1; PhoRC; SAM domain; Polycomb response element; Drosophila]

Supplemental material is available for this article.

Received February 8, 2016; revised version accepted April 13, 2016.

Polycomb group (PcG) proteins are transcriptional regulators that maintain cell fate decisions in animals and plants by repressing transcription of developmental regulator genes in cells where these genes should remain inactive. In Drosophila, 18 different proteins are classified as PcG members because animals lacking any of these proteins show widespread misexpression of Hox and other developmental regulator genes. Biochemical purification of these proteins revealed that these proteins are the subunits of four distinct protein complexes: Polycombrepressive complex 1 (PRC1), PRC2, Pho-repressive complex (PhoRC), and Polycomb-repressive deubiquitinase (PR-DUB) (Shao et al. 1999; Czermin et al. 2002; Müller et al. 2002; Klymenko et al. 2006; Scheuermann et al. 2010). Protein assemblies identical or related to PRC1, PRC2, and PR-DUB have also been purified from mammalian cells (Cao et al. 2002; Kuzmichev et al. 2002; Levine et al. 2002; Machida et al. 2009; Sowa et al. 2009; Yu et al. 2010; Gao et al. 2012).

PcG protein complexes repress transcription of target genes by modifying their chromatin (for review, see Simon and Kingston 2013). Biochemical and genetic studies have provided compelling evidence that the trimethylation of Lys27 in histone H3 by PRC2 (Cao et al. 2002; Czermin

Corresponding authors: muellerj@biochem.mpg.de, benda@biochem.mpg.de Article is online at http://www.genesdev.org/cgi/doi/10.1101/gad.279141.116. et al. 2002; Kuzmichev et al. 2002; Müller et al. 2002) and the capacity of PRC1 to compact chromatin (Francis et al. 2001, 2004; Grau et al. 2011) are critical for repression of PcG target genes in vivo (King et al. 2005; Eskeland et al. 2010; Isono et al. 2013; Pengelly et al. 2013; McKay et al. 2015). In contrast, the monoubiquitylation of histone H2A by PRC1 (Wang et al. 2004a), long considered to be a critical step for gene silencing by the PcG machinery (e.g., Stock et al. 2007), was recently shown to be dispensable for repression of canonical PRC1 target genes in both Drosophila (Pengelly et al. 2015) and mice (Illingworth et al. 2015).

The molecular interactions that permit PRC1 or PRC2 to associate with specific genomic locations are currently only poorly understood. Studies in mammalian cells have suggested that targeting of these complexes to DNA may entail binding to transcription factors, long noncoding RNAs, nonmethylated CpG dinucleotides in $\mathrm{CpG}$ islands, or methylated lysines in histone proteins (for review, see Klose et al. 2013; Simon and Kingston 2013). Despite this wealth of reported interactions,

(C) 2016 Frey et al. This article is distributed exclusively by Cold Spring Harbor Laboratory Press for the first six months after the full-issue publication date (see http://genesdev.cshlp.org/site/misc/terms.xhtml). After six months, it is available under a Creative Commons License (Attribution-NonCommercial 4.0 International), as described at http:// creativecommons.org/licenses/by-nc/4.0/. 
structural information about these is currently available only for the binding of PRC1 and PRC2 subunits to methylated lysine residues in histone proteins (Fischle et al. 2003; Min et al. 2003; Grimm et al. 2007, 2009; Santiveri et al. 2008; Guo et al. 2009; Margueron et al. 2009; Jiao and Liu 2015). Progress toward elucidating the molecular basis of PcG protein complex targeting has come from studies in Drosophila, where PcG protein complexes assemble at Polycomb response elements (PREs). PREs typically comprise a few hundred base pairs and contain binding sites for the PhoRC subunit Pho, the only PcG protein with sequence-specific DNA-binding activity (Brown et al. 1998; Kwong et al. 2008; Oktaba et al. 2008; Schuettengruber et al. 2009). The molecular basis of how Pho binds to PRE DNA is known from the cocrystal structure of the human Pho homolog YY1 bound to its cognate DNA-binding site (Houbaviy et al. 1996); the YY1 residues contacting DNA are 100\% conserved in Pho (Brown et al. 1998). Early studies proposed that the Pho spacer, a region of 30 amino acids that is highly conserved in mammalian YY1, directly interacts with different subunits of PRC1 or PRC2 (Mohd-Sarip et al. 2002, 2005; Wang et al. 2004b). However, attempts to reconstitute stable Pho:PRC2 or Pho:PRC1 assemblies with recombinant proteins have failed (Mohd-Sarip et al. 2005; Klymenko et al. 2006), and the molecular basis of the proposed interactions of Pho with the diverse PRC2 or PRC1 subunits has remained elusive. Recent structural studies revealed that the Pho spacer forms the interaction domain by which Pho binds its PhoRC partner subunit, Sfmbt (Alfieri et al. 2013). This finding, together with the observations that Sfmbt is co-bound with Pho at PREs genome-wide (Oktaba et al. 2008) and that Sfmbt association with PREs depends on intact Pho protein-binding sites in vitro and in vivo (Klymenko et al. 2006; Alfieri et al. 2013), suggest that Sfmbt rather than Pho itself may represent the docking platform for interaction with PRC1 and/or PRC2. In support of such a scenario, the PRC1 accessory subunit Scm interacts with recombinant Sfmbt protein in vitro (Grimm et al. 2009), but the molecular basis of this interaction is not known.
Here, we set out to purify proteins that associate with canonical PRC1 in Drosophila embryos and identified PhoRC as a major interactor of this complex. We found that the SAM domains of Sfmbt and Scm mediate the interaction between the two complexes and determined the crystal structure of the Sfmbt-SAM:Scm-SAM complex to reveal the recognition mechanism. Functional tests in Drosophila show that the Sfmbt-SAM:Scm-SAM interaction is critical for long-term PcG repression of target genes and that PRC1 association with PREs requires DNAbound PhoRC. Together, these studies thus reveal the molecular basis of how PhoRC targets PRC1 to PREs.

\section{Results}

\section{Biochemical purification identifies PhoRC as an interaction partner of PRC1}

To identify proteins that associate with the PRC1 subunit polyhomeotic-proximal (Ph-p) or its paralog, polyhomeotic-distal (Ph-d), we performed tandem affinity purification (TAP) (Rigaut et al. 1999) on nuclear extracts from transgenic Drosophila embryos expressing TAP-tagged Ph-p or Ph-d, respectively (Supplemental Fig. S1A). The TAP-Ph-p and TAP-Ph-d fusion proteins were expressed at levels comparable with endogenous Ph-p and Ph-d proteins (Supplemental Fig. S1B), and either protein was able to rescue the severe phenotype of $p h^{O}$ mutant embryos (Supplemental Fig. S1C), demonstrating that the fusion proteins could functionally substitute Ph-p and Ph-d. Mass spectrometric analyses of the purified material identified the PRC1 core subunits Psc, Su(z)2, Sce, and Pc and, intriguingly, also the PhoRC subunit Sfmbt as possible interaction partners of either Ph-p or Ph-d (Supplemental Fig. S1D; Supplemental Table S1). Western blot analysis confirmed that PRC1 and Sfmbt are enriched in TAP$\mathrm{Ph}-\mathrm{p}$ and TAP-Ph-d purifications and revealed that the purified assembly also contains the PRC1 accessory subunit Scm (Fig. 1A). The finding that PhoRC subunits are associated with PRC1 in Drosophila nuclear extracts is consistent with earlier studies that identified PhoRC subunits in
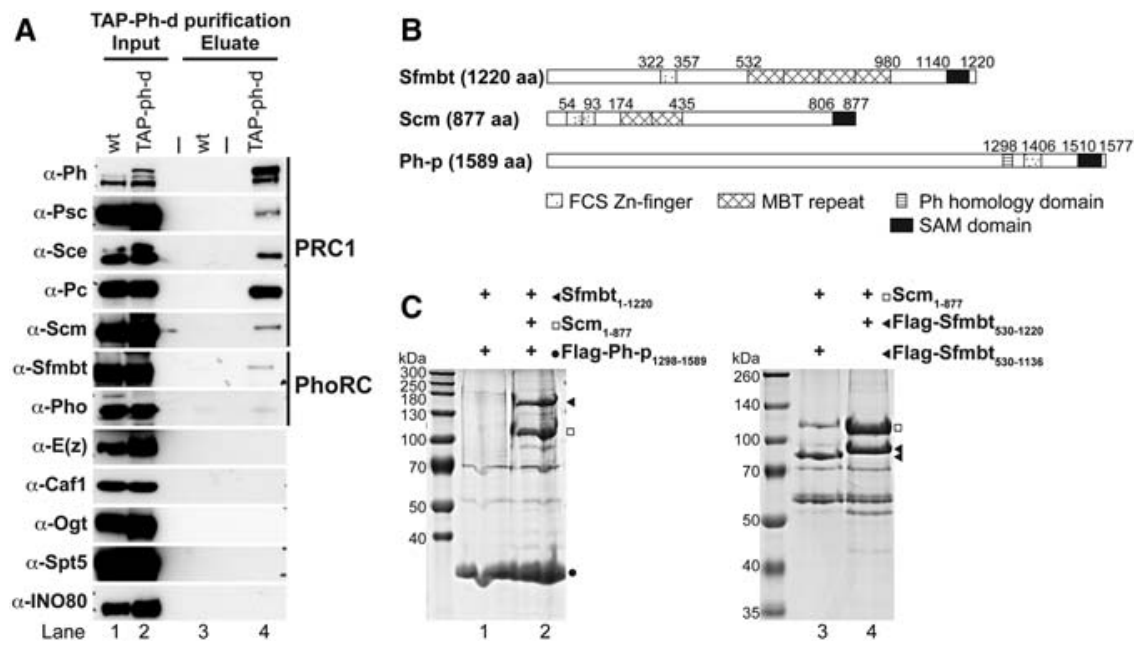

Figure 1. PRC1 and PhoRC interact in Drosophila via direct binding of Scm to Sfmbt. (A) Western blot analysis of material isolated by TAP from wild-type (wt) and $\alpha$ tubulin1-TAP-Ph-d transgenic embryos. Total nuclear extract input (lanes 1,2) and material eluted from calmodulin affinity resin after purification (lane 4) and mock purification (lane 3) were probed with the indicated antibodies. Only PRC1 subunits and Sfmbt are clearly enriched in lane 4 and undetectable in lane 3 . See the text for details. (B) Domain architecture of Sfmbt, Scm, and Ph. (C) Coomassie-stained SDS-PAGE gels of Flag affinity-purified material from Sf9 cells coexpressing the indicated proteins. See the text for details. 
Pc protein assemblies purified from Drosophila embryonic nuclear extracts (Strübbe et al. 2011) and in Pc and Scm chromatin assemblies purified from embryos after cross-linking (Kang et al. 2015). Moreover, this association also appears to be conserved in vertebrates where canonical PRC1 subunits were identified in purifications of Sfmbt1 and Sfmbt2 from human cells (Zhang et al. 2013).

\section{Sfmbt and Scm interact through the C-terminal SAM domains}

We next wanted to identify the molecular basis of the PRC1-PhoRC interaction. We previously found that, upon coexpression in insect cells, Scm and Sfmbt can be isolated as a stable dimeric complex (Grimm et al. 2009). Scm itself associates with PRC1 by binding to Ph, an interaction that is mediated by the SAM domains that are present in the $\mathrm{C}$ termini of both proteins (Fig. 1B; Peterson et al. 1997, 2004; Kim et al. 2005). To test whether Sfmbt may also interact with $\mathrm{Ph}$, we coexpressed Sfmbt with Flag-tagged Ph-p ${ }_{1298-1589}$, a C-terminal fragment of Ph-p that has high sequence identity with $\mathrm{Ph}-\mathrm{d}$ and contains the three structural domains in $\mathrm{Ph}$ proteins (Fig. 1B; Supplemental Fig. S1A). However, Flag affinity purification resulted in the isolation of Flag-Ph$\mathrm{p}_{1298-1589}$ alone (Fig. 1C, lane 1), suggesting that Sfmbt and $\mathrm{Ph}-\mathrm{p}$ do not interact directly. In contrast, coexpression of Scm together with Sfmbt and Flag-Ph- p $_{1298-1589}$ protein permitted isolation of a stable complex containing all three proteins (Fig. 1C, lane 2). This suggested that $\mathrm{Scm}$, binding to both $\mathrm{Ph}$ and Sfmbt, may act as the physical link that mediates the interaction between PRC1 and PhoRC.

These results prompted us to examine how Sfmbt and Scm bind to each other. Initial studies using C-terminally truncated Sfmbt and Scm proteins had suggested that the two proteins interact through poorly defined regions in their N termini (Grimm et al. 2009). However, we found that a Flag-Sfmbt ${ }_{530-1220}$ protein that lacks the previously described $\mathrm{N}$-terminal Scm-interacting region is also able to form a stable complex with Scm (Fig. 1C, lane 4), suggesting an additional $\mathrm{Scm}$-interacting region in the $\mathrm{C}$ terminus of Sfmbt. Deletion of the C-terminal SAM domain in Sfmbt substantially reduced the ability of this truncated Flag-Sfmbt ${ }_{530-1136}$ protein to bind to Scm (Fig. 1C, lane 3). This suggested that the Sfmbt SAM domain is important for binding to Scm.

Previous structural studies showed that the SAM domains of Scm and $\mathrm{Ph}$ both contain a mid-loop (ML) and an end helix (EH) surface (Fig. 2A) and have the propensity to form homopolymers or heteropolymers in a head-totail fashion where the EH surface of one SAM domain interacts with the ML surface of the SAM domain-binding partner (Kim et al. 2002, 2005). Work on Scm-SAM:PhSAM heteropolymers revealed that this assembly occurs in a defined orientation with preferential binding of the Scm-SAM EH surface to the Ph-SAM ML surface (Kim et al. 2005). Intriguingly, we found that recombinant Sfmbt-SAM ${ }_{1137-1220}$ (referred to as Sfmbt-SAM), if ex- pressed alone, eluted in a single peak corresponding to a monomer when purified on a gel filtration column (Supplemental Fig. S2A). The Sfmbt-SAM domain thus lacks the capacity to form homopolymers. We next tested whether Sfmbt-SAM might bind to the Scm-SAM domain. Considering that Sfmbt, Scm, and Ph can form a trimeric complex and that the EH surface of ScmSAM engages in binding to Ph-SAM, we hypothesized that Sfmbt might bind to the ML surface of Scm-SAM. In a first set of pull-down experiments, we found that Scm-SAM ${ }_{803-877}$ in which the EH surface had been mutated $\left(\mathrm{Scm}-\mathrm{SAM}^{\mathrm{L} 855 \mathrm{E} / \mathrm{L} 859 \mathrm{E}}\right)$ to prevent the formation of Scm-SAM homopolymers bound to GSTSfmbt-SAM (Supplemental Fig. S2B). In contrast, Ph-SAM ${ }^{\mathrm{L} 1561 \mathrm{E} / \mathrm{L} 1565 \mathrm{E}}$ containing the corresponding $\mathrm{EH}$ surface mutations to prevent Ph-SAM homopolymer formation interacted only very poorly with GST-SfmbtSAM in the same assay (Supplemental Fig. S2B). We then coexpressed Sfmbt-SAM and Scm-SAM ${ }^{\mathrm{L} 855 \mathrm{E} / \mathrm{L} 859 \mathrm{E}}$ and found that the Sfmbt-SAM:Scm-SAM ${ }^{\mathrm{L} 855 \mathrm{E} / \mathrm{L} 859 \mathrm{E}} \mathrm{com}$ plex (referred to here as Sfmbt-SAM:Scm-SAM) eluted as a single peak corresponding to a dimer on a gel filtration column (Fig. 2B; Supplemental Fig. S2A), suggesting that these two SAM domains form a stable complex.

\section{Structure of the Sfmbt-SAM:Scm-SAM complex}

We obtained diffracting crystals of the Sfmbt-SAM:ScmSAM dimer. We solved the structure by molecular replacement with Ph-SAM:Scm-SAM as a search model and refined it to $1.9 \AA$ resolution $\left(\mathrm{R}_{\text {free }}\right.$ of $27.7 \%$ and $\mathrm{R}_{\text {work }}$ of $25.5 \%$ ). The asymmetric unit contained two SfmbtSAM:Scm-SAM dimers that interacted laterally. This lateral interaction between the two dimers is likely imposed by crystal packing because Sfmbt-SAM:Scm-SAM behaves as a heterodimer in gel filtration chromatography even at high concentrations (Fig. 2B), and, moreover, one of the two interactions between the dimers is a salt bridge formed by the mutated $\mathrm{Scm}^{\mathrm{L} 859 \mathrm{E}}$ residue (data not shown). In the following, we thus consider the Sfmbt-SAM:ScmSAM complex to exist as a dimer.

The structure revealed that the Sfmbt-SAM domain is a helical bundle with the canonical SAM domain fold (Fig. 2C). The major interaction in the dimer is between the EH surface of Sfmbt-SAM and the ML surface of ScmSAM and covers an area of $\sim 550 \AA^{2}$ (calculated with PDBePISA [proteins, interfaces, structures, and assemblies]) (Fig. 2C). The interface comprises a hydrophobic region and an adjacent polar region. The hydrophobic interactions involve the side chains of A838, L841, L842, M846, and Y850 on the Scm ML surface and M1180, V1187, G1188, and L1191 on the Sfmbt EH surface (Fig. 2C right, top panel). The adjacent polar interactions are formed by three salt bridges $\left(\mathrm{E} 833^{\mathrm{Scm}}-\mathrm{K} 1186^{\mathrm{Sfmbt}}\right.$, D835 $5^{\mathrm{Scm}}$ $\mathrm{K} 1192^{\text {Sfmbt }}$, and K849 ${ }^{\text {Scm }}-\mathrm{D} 1177^{\text {Sfmbt }}$ and hydrogen bonds between backbone $\left[\mathrm{H} 832^{\mathrm{Scm}}(\mathrm{O})-\mathrm{G} 1188^{\mathrm{Sfmbt}}(\mathrm{N})\right]$ and side chains (Y850 ${ }^{\mathrm{Scm}}$-D1 $\left.177^{\mathrm{Sfmbt}}\right)$ (Fig. 2C, right, bottom panel). Two water molecules bridging $\mathrm{Y}^{2} 50^{\mathrm{Scm}}$ with $\mathrm{D} 1177^{\text {Sfmbt }}$ and E833 ${ }^{\mathrm{Scm}}$ with K1192 ${ }^{\text {Sfmbt }}$ further stabilize the interface (data not shown). 

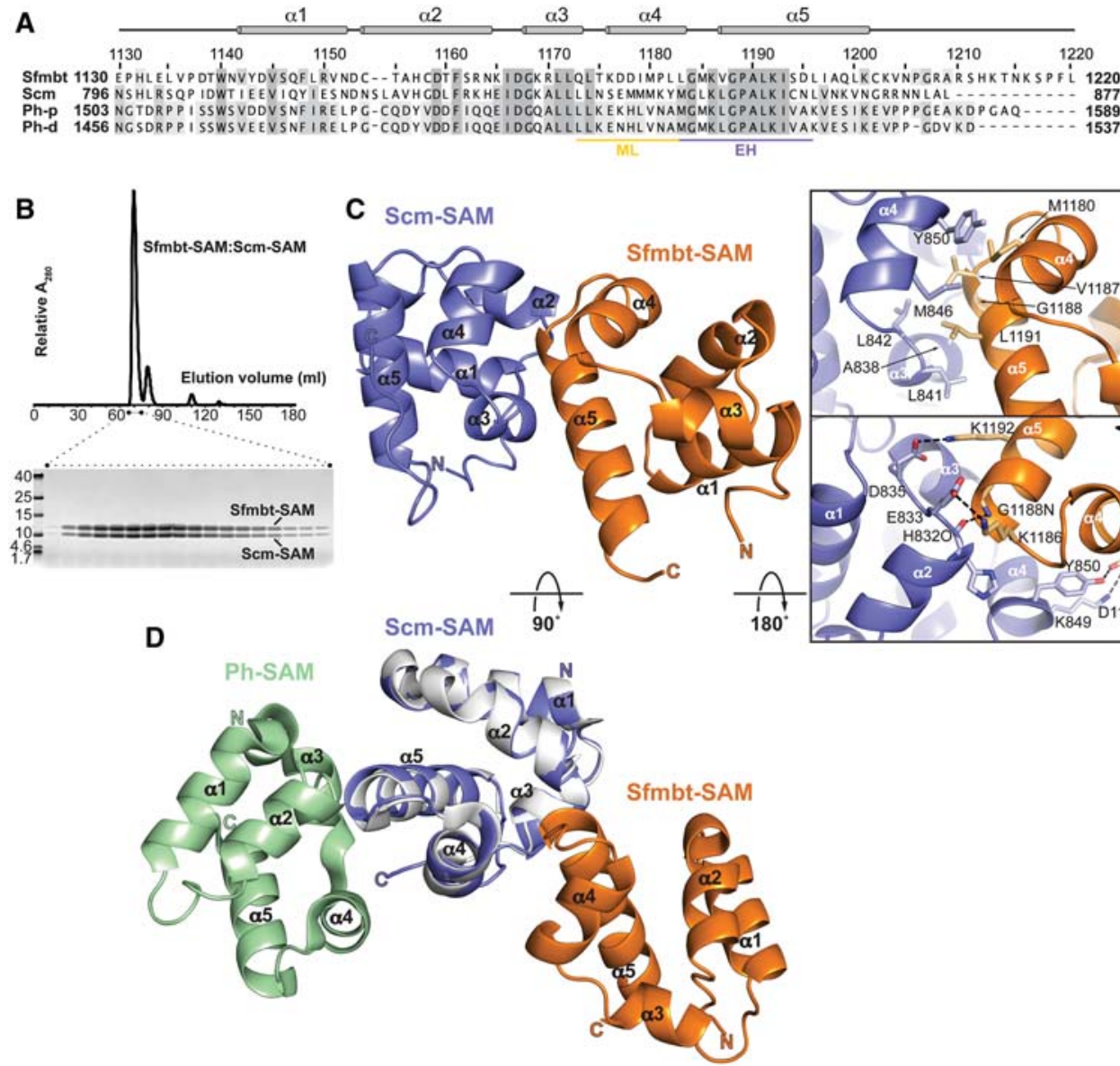

Figure 2. Structural analysis of the Sfmbt-SAM:Scm-SAM interaction. (A) Sequence alignment of the SAM domains of Sfmbt, Scm, Ph-p, and Ph-d. The ML (light orange) and EH (purple) surfaces are highlighted. (B) Elution profile of the Sfmbt-SAM:Scm-SAM complex and Coomassie-stained SDS-PAGE of peak fractions. (C) Crystal structure of the Sfmbt-SAM:Scm-SAM complex in ribbon diagram presentation. Close-up view of the Sfmbt-SAM:Scm-SAM complex interface. Hydrophobic residues (top panel) and polar residues (bottom panel) that form the interaction surface are depicted. Hydrogen bonds and salt bridges are indicated (dashed lines). See the text. (D) Structural superposition of the Sfmbt-SAM:Scm-SAM complex with the Scm-SAM:Ph-SAM complex (Protein Data Bank [PDB] ID 1PK1) to model a trimeric complex containing the SAM domains of Sfmbt, Scm, and Ph.

\section{The ML surface of Sfmbt-SAM lacks the capacity for forming SAM-SAM interactions}

Inspection of the ML surface of the Sfmbt-SAM domain explains why this domain lacks polymerization capacity. In Sfmbt, a number of residues at positions corresponding to the apolar residues in the Scm ML surface are substituted with polar residues. In particular, R1170 in the ML surface of Sfmbt-SAM, corresponding to a conserved Ala in Scm-SAM and Ph-SAM (Fig. 2A), would block interaction with the EH surface of another SAM domain. This provides a likely explanation of why Sfmbt-SAM can engage in interaction with only a single SAM domain partner via the EH surface.

Molecular basis for the formation of extended Sfmbt-Scm-Ph assemblies

Because Scm-SAM adopts the same conformation in Sfmbt-SAM:Scm-SAM and Scm-SAM:Ph-SAM (Protein
Data Bank [PDB] ID 1PK1), the two complexes can easily be superimposed via their common Scm-SAM domains (root mean square deviation [RMSD] of 0.42 over $67 \mathrm{Ca}$ ). This superposition permitted us to generate a model of the trimeric Sfmbt-SAM:Scm-SAM:Ph-SAM complex (Fig. 2D). In support of this, we reconstituted a complex containing all three SAM domains by coexpressing

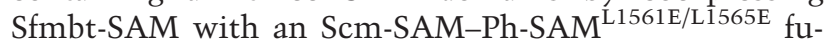
sion protein (Supplemental Fig. S2C). On a gel filtration column, the major peak contained stoichiometric amounts of the two polypeptides (Supplemental Fig. $\mathrm{S} 2 \mathrm{C}$. We presume that this defined complex containing all three SAM domains is formed because the fusion protein promotes the intramolecular interaction of ScmSAM with Ph-SAM and thus effectively limits the oligomerization capacity of Scm-SAM, leaving its ML surface available for interaction with Sfmbt-SAM.

In each of the three proteins, the SAM domain is located at the very $\mathrm{C}$ terminus and is separated from adjacent domains by linker regions that are predicted to be mostly 
disordered (Fig. 1B). Therefore, even though the SAM polymer assumes a rigid conformation, these adjacent linker sequences likely allow flexibility for orientation of the rest of each protein. It is important to recall that both Scm-SAM and Ph-SAM have the capacity to form homopolymers or heteropolymers. PRE-tethered Sfmbt, lacking this polymerization capacity, may therefore act as an assembly platform to initiate formation of longer polymers containing $\mathrm{Scm}$ and/or Ph proteins that emanate from PREs.

\section{The SAM domains of Sfmbt and Scm are essential for target gene repression}

We next investigated the requirement of the Sfmbt-SAM and Scm-SAM domains for transcriptional repression of PcG target genes in Drosophila. In a first set of experiments, we tested whether Sfmbt ${ }^{\Delta \mathrm{SAM}}$ lacking the SAM domain can replace the endogenous Sfmbt protein in a genetic rescue assay in larvae, as follows: In the wing imaginal disc, clones of cells that are homozygous for the $S f m b t^{1}$-null mutation fail to maintain PcG repression of the Hox gene Ultrabithorax $(U b x)$, and the Ubx protein becomes strongly misexpressed in the mutant clones (Fig. 3A, left). When such Sfmbt $t^{1}$ mutant clones were induced in animals carrying a transgene with a genomic fragment expressing wild-type Sfmbt protein, the transgene-encoded Sfmbt protein fully rescued repression, and no Ubx protein was detected in the $S f m b t^{1}$ homozygous cells (Fig. 3A, middle). In contrast, the Sfmbt ${ }^{\Delta S A M}$ protein expressed from the same genomic fragment was inefficient in rescuing repression, and the Ubx protein was strongly misexpressed in a large fraction of $S f m b t^{1}$
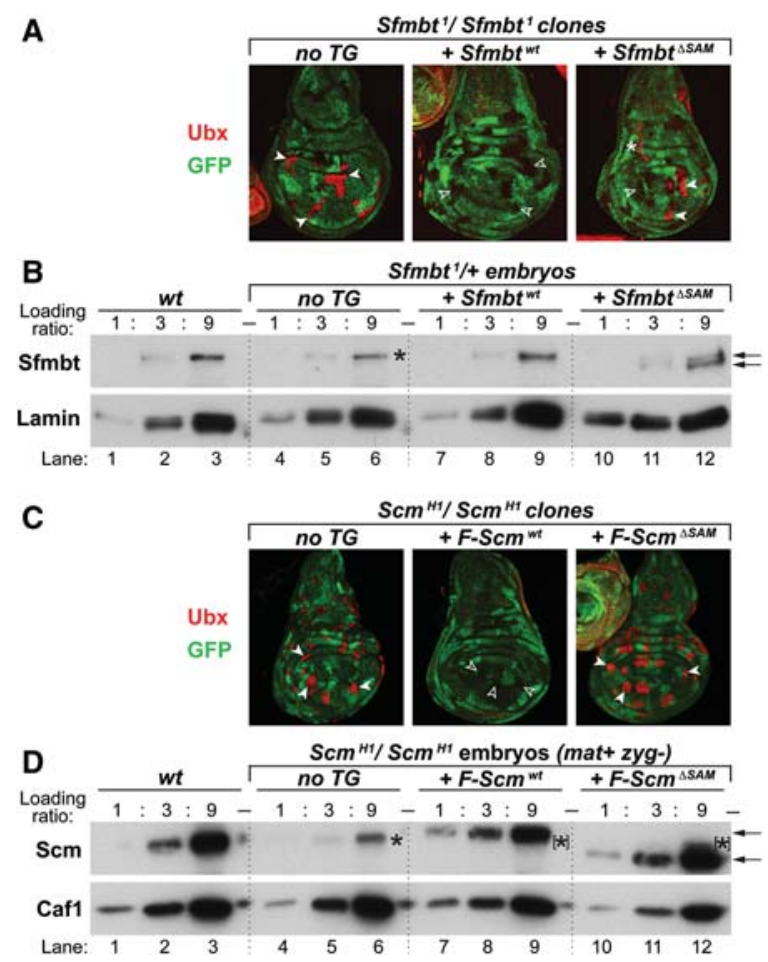

homozygous cells (Fig. 3A, right). Importantly, the truncated Sfmbt ${ }^{\triangle S A M}$ protein was stable and present at levels comparable with that of the wild-type Sfmbt protein (Fig. 3B). Together, these results show that the SAM domain is critical for Sfmbt to function in PcG repression. The comparison of the repression defects in $S f m b t^{\Delta S A M}$ and $S f m b t$-null mutant clones nonetheless suggests that the $S f m b t^{\triangle S A M}$ protein retains partial repressor function (Fig. 3A), suggesting that deletion of the SAM domain does not completely incapacitate the protein.

Figure 3. SAM domains of Sfmbt and $\mathrm{Scm}$ are required for PcG repression. (A) Imaginal wing discs with clones of $S \mathrm{mbt} t^{1}$ homozygous cells from animals that carried no transgene (no TG) or the indicated genomic transgenes expressing wild-type Sfmbt $\left(\mathrm{Sfmbt}^{\mathrm{wt}}\right)$ or Sfmbt ${ }^{\Delta \mathrm{SAM}}$ stained with antibody against Ubx protein (red). Clones of $S \mathrm{mbt}^{1}$ homozygous cells are marked by the lack of GFP (green) and were induced $72 \mathrm{~h}$ before analysis. Only Sfmbt ${ }^{1}$ homozygous cells (no TG) in the wing pouch (arrowheads) but not in the notum or hinge show strong misexpression of Ubx (Klymenko et al. 2006), and rescue of Ubx repression by $S f m b t^{\mathrm{wt}}$ or Sfmbt ${ }^{\Delta \mathrm{SAM}}$ was therefore only analyzed in clones in the wing pouch area. In no TG animals, $98,4 \%$ of $S f m b t^{1}$ homozygous clones ( $n=63$ clones) showed misexpression of Ubx (arrowheads). In animals carrying $S f m b t^{w t}$, repression of Ubx was rescued in most $S f m b t^{1}$ homozygous clones (empty arrowheads), and only $1 \%$ of clones ( $n=104$ clones) showed misexpression of Ubx. In animals carrying $S f m b t^{\Delta S A M}, 55 \%$ of $S f m b t^{1}$ homozygous clones ( $n=159$ clones) showed misexpression of Ubx (arrowheads). Thus, even though the Sfmbt ${ }^{\Delta \mathrm{SAM}}$ protein largely fails to rescue, the repression of Ubx in $45 \%$ of clones (empty arrowheads) suggests that the Sfmbt ${ }^{\Delta \mathrm{SAM}}$ protein retains some repressor activity. An asterisk marks normal $U b x$ expression in a trachea attached to the disc. $(B)$ Western blots on serial dilutions (9:3:1) of extracts from whole nuclei of 0- to 12-h-old embryos of the indicated genotypes probed with antibodies against Sfmbt and, as a loading control on the same membrane, Lamin. The asterisk marks the band of wild-type Sfmbt in Sfmbt ${ }^{1}$ heterozygotes. Note that in lanes 10-12, the levels of Sfmbt ${ }^{\Delta \mathrm{SAM}}$ and endogenous wild-type Sfmbt (bottom and top arrows, respectively) are comparable. (C) Analysis of Ubx repression as in $A$ but in clones of $\mathrm{Scm}^{\mathrm{H1}}$ homozygous cells in animals carrying no transgene (no TG) or transgenes expressing Flag-tagged wild-type Scm $\left(\mathrm{F}-\mathrm{Scm}^{\mathrm{wt}}\right)$ or F-Scm ${ }^{\Delta \mathrm{SAM}}$. Scm ${ }^{H 1}$ homozygous clones marked by a lack of GFP (green) were induced $72 \mathrm{~h}$ before analysis. Only clones in the pouch were analyzed for statistics. In no TG animals, $100 \%$ of $\mathrm{Scm}^{H 1}$ homozygous clones ( $n=94$ clones) showed misexpression of Ubx (arrowheads). F-Scm ${ }^{\mathrm{wt}}$ rescued repression of Ubx in all clones (empty arrowheads), and none of the clones $(n=42$ clones) showed misexpression of Ubx, consistent with the lack of a phenotype in $S \mathrm{~cm}$-null mutant adults that are rescued by this transgene (Peterson et al. 2004). In animals carrying F$\mathrm{Scm}^{\Delta \mathrm{SAM}}, 100 \%$ of $\mathrm{Scm}^{H 1}$ homozygous clones ( $n=130$ clones $)$ showed misexpression of Ubx (arrowheads). See also Supplemental Figure S3. (D) Western blots on serial dilutions (9:3:1) of total extracts from 14- to 18-h-old embryos of the indicated genotypes probed with antibodies against Scm and, as loading control on the same membrane, Caf1. An asterisk marks maternally deposited wild-type Scm protein that persists in $\mathrm{Scm}^{H 1}$ homozygous embryos; in lanes $7-12$, this band is partially obscured ([*]) by the bands from the transgene-encoded F-Scm ${ }^{\mathrm{wt}}$ and F-Scm ${ }^{\triangle S A M}$ proteins (top and bottom arrows, respectively). 
Next, we assessed the requirement of the Scm-SAM domain. Previous studies showed that a transgene containing a genomic Scm fragment rescues Scm-null mutant animals into viable and fertile adults but that an $\mathrm{Scm}^{\Delta \mathrm{SAM}}$ protein expressed from the same genomic fragment fails to rescue viability of these animals (Peterson et al. 2004). To extend this finding, we tested the capacity of the $\mathrm{Scm}^{\triangle \mathrm{SAM}}$ protein to repress PcG target genes in clones of Scm-null mutant cells. Only the transgene expressing wild-type Scm protein was able to rescue repression of $U b x$ in clones of cells that were homozygous for the $\mathrm{Scm}^{H 1}$-null mutation (Fig. $3 \mathrm{C}$ ). The $\mathrm{Scm}^{\Delta \mathrm{SAM}}$ protein completely lacked Scm repressor activity, and the Ubx protein was as widely misexpressed as in $\mathrm{Scm}^{\mathrm{H1}}$ mutant clones in animals carrying no transgene (Fig. 3C). In parallel, we also assayed the rescue capacity of the $\mathrm{Scm}^{\Delta \mathrm{SAM}}$ protein in embryos that were homozygous for $\mathrm{Scm}^{\mathrm{H1}}$ (Supplemental Fig. S3). Only the transgene-encoded wildtype $\mathrm{Scm}$ protein, but not the $\mathrm{Scm}^{\Delta \mathrm{SAM}}$ protein, was able to rescue repression of the Hox gene Abdominal- $B$ $(A b d-B)$ in $S_{c m}^{H 1}$ homozygous embryos (Supplemental Fig. S3). As previously reported (Peterson et al. 2004), we found that the $\mathrm{Scm}^{\triangle \mathrm{SAM}}$ protein is stable and expressed at levels comparable with that of the wild-type Scm protein (Fig. 3D). Together, these results show that the ScmSAM domain is essential for Scm to function in PcG repression.

Finally, we note that similar structure/function analyses of the Ph protein in Drosophila recently demonstrated that the Ph SAM domain is essential for all functions of $\mathrm{Ph}$ (Gambetta and Müller 2014). Taken together, these data thus show that deletion of the SAM domain in Sfmbt, $\mathrm{Scm}$, or $\mathrm{Ph}$ in each case ablates protein function.

\section{PhoRC DNA-binding is critical for PRC1 recruitment to a PRE}

We next investigated the requirement of PhoRC for recruitment of PRC1 to PREs in developing Drosophila. A number of limitations precluded us from monitoring PRC1 binding in Sfmbt or pho phol mutant animals by chromatin immunoprecipitation (ChIP) assays. First, it is not possible to generate embryos lacking maternally deposited PhoRC because the complex is essential for germ cell development (Breen and Duncan 1986; Girton and Jeon 1994; Brown et al. 2003; Klymenko et al. 2006). Consequently, in Sfmbt or pho phol zygotic mutant embryos, maternally deposited wild-type PhoRC permits almost normal establishment of PcG repression (Simon et al. 1992; Brown et al. 2003; Klymenko et al. 2006). Second, as the Sfmbt and pho phol zygotic mutant animals that develop into larvae are becoming depleted of maternally supplied PhoRC, the diploid larval cells begin to show defects in proliferation and form only poorly developed central nervous system (CNS) and rudimentary imaginal disc tissues (Brown et al. 2003; Klymenko et al. 2006), making these tissues unreliable material for ChIP analysis.

As an alternative approach to analyze PRC1 recruitment to PREs in the absence of PhoRC, we analyzed bind- ing at a PRE transgene with mutated Pho/Phol-binding sites. $P R E_{D}$, a 570-base-pair (bp)-long fragment containing the core of the bxd PRE in Ubx, contains six Pho proteinbinding sites (Chan et al. 1994; Fritsch et al. 1999). Previous studies in embryos showed that Pho, Sfmbt, and Ph bind to the wild-type $P R E_{D}$ in a transgene but that this binding was strongly reduced at a $P R E_{D}$ pho mut transgene in which the Pho-binding sites had been mutated (Fritsch et al. 1999; Klymenko et al. 2006). Here, we performed ChIP assays in imaginal wing discs from $P R E_{D}$ or $P R E_{D}$ pho mut transgenic larvae to monitor binding of the Pho, Sfmbt, Scm, and $\mathrm{Ph}$ proteins in the same tissues where we investigated the function of the Sfmbt-SAM and Scm-SAM domains (Fig. 3). In addition, we also analyzed binding of the Trithorax (Trx) protein, the PRC2 core subunit E(z), and the levels of the H3K27me3 mark. Binding of each of these proteins at the native $b x d P R E$ in $U b x$, at the iab-7 PRE in $A b d-B$, and at other genomic regions not bound by PcG proteins served as internal controls in the two transgenic lines (Fig. 4A). The Pho, Sfmbt, Scm, and $\mathrm{Ph}$ proteins were all bound at the wild-type $P R E_{D}$ transgene, but, for each protein, only very low-level binding was detected at the $P R E_{D}$ pho mut transgene (Fig. 4A). In contrast, binding of the Trx protein was comparable at the $P R E_{D}$ and $P R E_{D}$ pho mut transgenes (Fig. 4A). E(z) and $\mathrm{H} 3 \mathrm{~K} 27 \mathrm{me} 3$ were strongly enriched at the $P R E_{D}$ transgene and drastically reduced at the $P R E_{D}$ pho mut transgene, consistent with earlier findings that suggested that Pho is required for association of PRC2 with PREs (Wang et al. 2004b). In summary, these analyses show that recruitment of PRC1 and also PRC2 to the bxd PRE critically depends on the ability of PhoRC to bind to Pho DNA-binding sites.

\section{Discussion}

Atomic-level information on the molecular interactions by which PcG protein complexes bind to the genes that they regulate is essential for understanding how the PcG system works. In Drosophila, the different PcG protein complexes assemble at PRE sequences in target genes. Previous structural studies showed how YY1, the mammalian ortholog of the PhoRC subunit Pho, recognizes its cognate DNA-binding site, providing an atomic model of how PhoRC binds to PRE DNA (Fig. 4B). More recent studies then revealed how Sfmbt interacts with the Pho spacer to form PhoRC (Fig. 4B). Here, we present the structural basis of how PhoRC binds to canonical PRC1 and provide functional evidence that this PhoRC-PRC1 interaction targets PRC1 to PRE DNA (Fig. 4).

The following main conclusions can be drawn from the work presented in this study. First, biochemical purification of canonical PRC1 from nuclear extracts of Drosophila identifies PhoRC but no other DNA-binding proteins among the most highly enriched PRC1 interactors. This observation is consistent with previous studies (Strübbe et al. 2011) and suggests that, in Drosophila, PhoRC is the main PRC1 interaction partner with sequence-specific DNA-binding activity. Second, biochemical reconstitution shows that the PRC1 subunit Scm and 


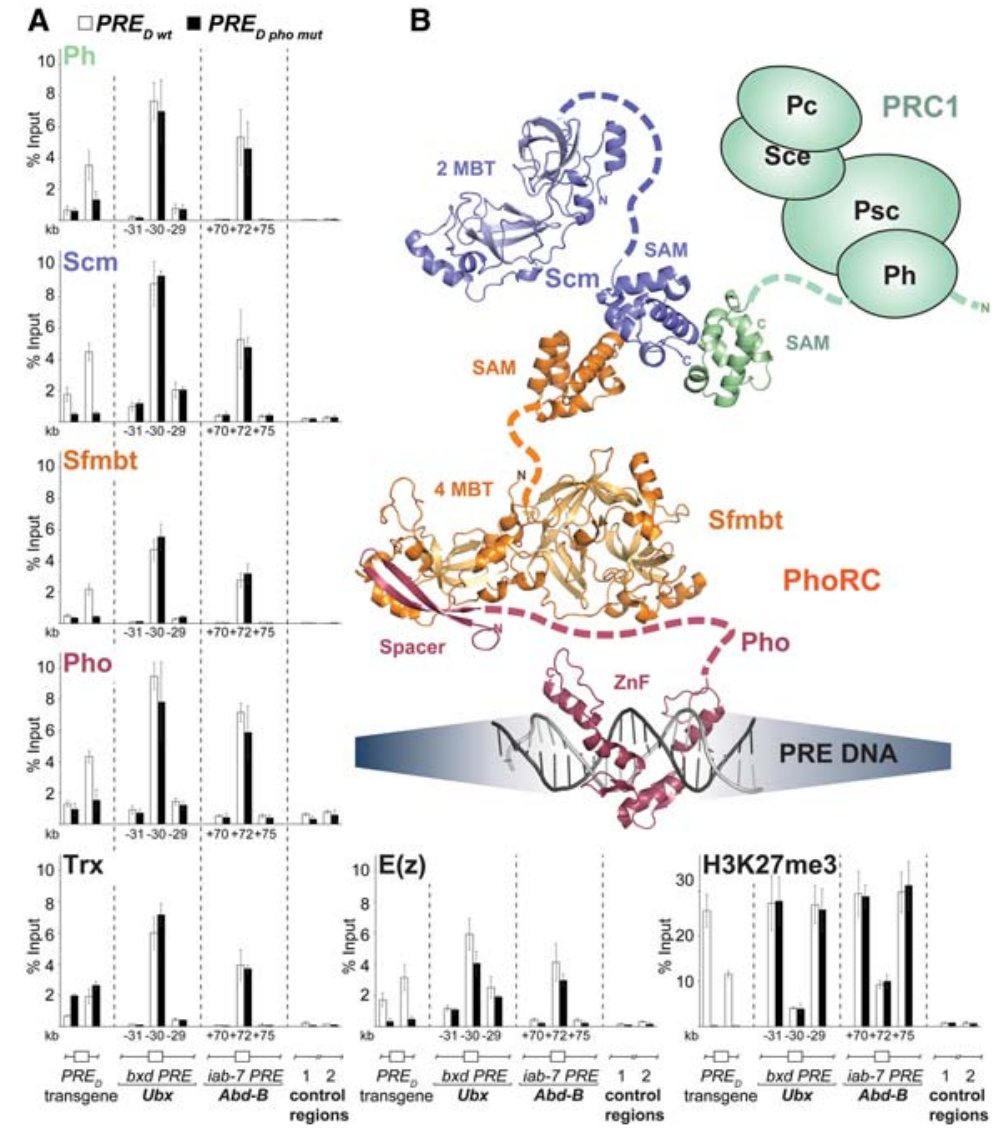

Figure 4. PRC1 tethering to PREs by the PhoRC complex. (A) Binding of PRC1 to the bxd PRE depends on Pho protein-binding sites. ChIP analysis monitoring binding of Ph, Scm, Sfmbt, Pho, Trx, and E(z) and the levels of $\mathrm{H} 3 \mathrm{~K} 27 \mathrm{me} 3$ in $P R E_{D}$ (white bars) and $P R E_{D}$ pho mut (black bars) transgenic animals. In $P R E_{D}$ transgenic animals, all proteins are specifically bound at $P R E_{D}$ and at the native $b x d$ and $i a b-7$ PREs, and no or only a low level of binding is detected in regions flanking these PREs and at two control regions 1 and 2 elsewhere in the genome (kilobase coordinates indicate location of $b x d$ and $i a b-7$ PREs with respect to $U b x$ and $A b d-B$ transcription start sites, respectively). (Left) In $P R E_{D}$ pho mut transgenic animals, binding of Pho, Sfmbt, Scm, Ph, E(z), and $\mathrm{H} 3 \mathrm{~K} 27 \mathrm{me} 3$ at $P R E_{D}$ pho mut is strongly reduced due to mutation of all six Pho protein-binding sites in this PRE fragment, whereas binding of Trx at $P R E_{D}$ pho mut is unchanged or even increased. Binding of all proteins and $\mathrm{H} 3 \mathrm{~K} 27 \mathrm{me} 3$ levels at the other regions in $\mathrm{PRE}_{\mathrm{D}}$ Pho mut animals are comparable with that in $\mathrm{PRE}_{\mathrm{D}}$ animals. Graphs represent results from three independent ChIP reactions on three separately prepared batches of chromatin; quantitative PCR signals are represented as percentage of input material precipitated in each immunoprecipitation reaction, and error bars show standard deviation. (B) Molecular model of interactions with which PhoRC tethers canonical PRC1 to PREs. The Pho/YY1 zinc finger domain (ZnF; purple) recognizes the Pho/YY1-binding motif GCCAT in a PRE DNA (PDB ID 1ubd) (Houbaviy et al. 1996). The Pho spacer region (purple) binds to the 4MBT domain of Sfmbt (orange) to form PhoRC (PDB ID 4C5I) (Alfieri et al. 2013). The ML surface of Scm-SAM (slate) binds to the EH surface of Sfmbt-SAM (orange) (this study), while the EH surface of Scm-SAM binds to the ML surface of Ph-SAM (green) (PDB ID 1PK1) (Kim et al. 2005)), providing a physical link between PhoRC and canonical PRC1. Binding of the 2MBT domain of Scm and the 4MBT domain of Sfmbt to monomethylated or dimethylated lysines in histone $\mathrm{N}$ termini (PDB ID 2R57 and 2R5A; 3h6z) (methylated histone peptides are not shown here) (Grimm et al. 2007, 2009) possibly provide additional binding interactions with nucleosomes in target gene chromatin.

the PhoRC subunit Sfmbt mediate this interaction by binding to each other through their C-terminal SAM domains. Third, the crystal structure of the Sfmbt-SAM: Scm-SAM complex reveals the recognition mechanism and uncovers that, unlike Scm-SAM and Ph-SAM, the Sfmbt-SAM domain lacks the capacity to oligomerize. Fourth, genetic analyses in Drosophila demonstrate that the SAM domains of Sfmbt and Scm are both essential for repression of PcG target genes, providing functional evidence for the importance of the Sfmbt-SAM:ScmSAM interaction. Fifth, binding of both PhoRC and PRC1 to a Hox gene PRE in Drosophila critically depends on intact DNA-binding sites for Pho, suggesting that PhoRC constitutes the binding platform for $\mathrm{PRCl}$ association with this PRE.

\section{The Sfmbt-Scm interaction links PhoRC and PRC1}

The PRC1-PhoRC assemblies isolated in this study and by Strübbe et al. (2011) were identified in affinity purifications of PRC1 from soluble nuclear extracts that had been prepared by high-salt extraction from embryonic nuclei of Drosophila. Although it is possible that PRC1 and PhoRC bind to each other in the nucleoplasm independently of
DNA, we consider it more likely that the PRC1-associated PhoRC in the purified material represents PRC1PhoRC assemblies that had formed at target gene DNA and were solubilized from chromatin during extract preparation. This scenario is also supported by ChIP profiling and proteomic analyses on cross-linked chromatin that showed that PhoRC and PRC1 colocalize at a large fraction of genomic target sites (Kwong et al. 2008; Oktaba et al. 2008; Schuettengruber et al. 2009; Kang et al. 2015).

The requirement of the Sfmbt-SAM and Scm-SAM domains for target gene repression supports the importance of their interaction. Nevertheless, we found that the $S f m b t^{\Delta S A M}$ protein is not completely incapacitated for repression (Fig. 3A). It is possible that interaction of $\mathrm{Sfmbt}^{\Delta \mathrm{SAM}}$ and $\mathrm{Scm}$ through a second interaction site in their $\mathrm{N}$ termini (Grimm et al. 2009) accounts for the repression in a fraction of Sfmbt ${ }^{\Delta S A M}$ mutant cells. The observation that the $\mathrm{Scm}^{\triangle \mathrm{SAM}}$ protein is nonetheless completely incapacitated for repression (Fig. 3C; Supplemental Fig. S3) is not at odds with this interpretation because deletion of the SAM domain in Scm not only compromises Scm binding to Sfmbt but also prevents Scm binding to the Ph SAM domain and thus association with PRC1 (Fig. 4B; Peterson et al. 2004; Kim et al. 2005). 
In this scenario, the Scm-SAM domain provides the critical physical link that mediates the interaction between PhoRC and PRC1 (Fig. 4B). It is possible that other, unidentified DNA-binding proteins are also able to recruit Scm to PREs (Wang et al. 2010). However, at least at the bxd PRE, the PhoRC-PRC1 link reported here appears to be critical for recruitment of PRC1 because binding of both $\mathrm{Scm}$ and $\mathrm{Ph}$ is strongly reduced if PhoRC binding to PRE DNA is compromised (Fig. 4A).

PRE-tethered Sfmbt-SAM:Scm-SAM as a nucleation site for short-and long-range chromatin organization

Current models suggest that PRC1 represses target gene transcription by altering chromatin organization at two different levels. First, Psc and CBX2 in Drosophila and vertebrate PRC1, respectively, act at the level of nucleosomes by compacting arrays of nucleosomes and inhibiting their remodeling in vitro (Francis et al. 2001, 2004; Grau et al. 2011). This activity relies on low-complexity regions in the Psc and CBX2 proteins that are rich in basic amino acids, and, in the case of Psc, these regions were shown to be essential for target gene repression in Drosophila (King et al. 2005). The PRC1 subunit Ph, on the other hand, appears to alter chromatin at a higher level of organization by changing chromatin topology in part by forming long-range contacts between distant Ph-bound chromosomal sites (Cheutin and Cavalli 2012; Isono et al. 2013; Boettiger et al. 2016; Wani et al. 2016). This activity requires the $\mathrm{Ph}-\mathrm{SAM}$ domain and its ability to form homo-oligomers or hetero-oligomers (Isono et al. 2013; Wani et al. 2016). The capacity of Ph-SAM to form oligomers is also strictly required for repression of PcG target genes in Drosophila (Gambetta and Müller 2014). The Sfmbt-SAM:Scm-SAM interaction reported here may thus provide the molecular basis toward understanding not only how PRE-tethered PRC1 locally compacts arrays of nucleosomes in the chromatin flanking PREs but also how it interacts with other PRC1 assemblies bound at distant chromosomal sites to form topologic domains of PcG-repressed chromatin.

\section{Materials and methods}

\section{TAP of Ph complexes}

The a-tubulin1-TAP-Ph- $p$ and a-tubulin1-TAP-Ph- $d$ transgenes in the previously described Drosophila transformation vector CaSpeR-NTAP (Nekrasov et al. 2007) contained a 2.6-kb fragment of the a-tubulin1 gene, including promoter and 5' untranslated region sequences, followed by the TAP tag and either the $\mathrm{Ph}-\mathrm{p}_{1-1589}$ or Ph- $\mathrm{d}_{1-1537}$ coding regions (plasmid maps are available on request). TAP from 0 - to 14-h-old embryonic nuclear extracts was performed as described (Klymenko et al. 2006).

\section{Mass spectrometric analysis of protein isolated by TAP}

We performed two independent purifications from extracts of TAP-Ph-d transgenic embryos and one from TAP-Ph-p transgenic embryos; in each case, a mock purification from wild-type embryos was performed in parallel. Calmodulin eluates were analyzed by SDS-PAGE, and proteins were visualized by Coomassie staining. For each sample, lanes were cut into five equal gel slices, and peptides were generated by tryptic in-gel digestion (Shevchenko et al. 2006).

Desalted peptide samples were analyzed using liquid chromatography-tandem mass spectrometry (LC-MS/MS) on a LTQ Orbitrap Velos instrument online coupled to an Easy-nLC system (both Thermo Fisher Scientific). Samples were analyzed using 65- and 90-min reversed-phase chromatography, respectively. Settings were set to $200 \mathrm{~nL} / \mathrm{min}$ flow and gradient from $5 \%$ to $30 \%$ solvent $\mathrm{B}(80 \% \mathrm{ACN}, 0.5 \% \mathrm{AcOH})$ for 43 and $65 \mathrm{~min}$, respectively. Mass spectrometric settings were as follows: full scan: $10^{6}$ ions, $100-\mathrm{msec}$ maximum filling times; MS2 scan: $4 \times 10^{4}$ ions, 150-msec maximum filling times; isolation width: 4; minimal signal required: $10^{3}$; and NCE: 40 . The 10 most intense ions were fragmented using HCD mode and fixed at $\mathrm{m} / \mathrm{z} 100$. Unassigned charges and singly charged ions were rejected from MS2 fragmentation. Dynamic exclusion was enabled.

All .RAW files were analyzed together using the MaxQuant software suite, including the Andromeda search engine (version 1.5.0.0; (Cox and Mann 2008; Tyanova et al. 2014). The analysis was performed on tryptic peptides, including fixed modifications of carbamidomethylation (Cys) and variable modifications of $\mathrm{N}$-terminal acetylation and oxidation of methionine. Files were searched against the UniProt database of Drosophila (18,796 entries) as well as the self-defined FASTA sequences of Ph-d and Ph-p. Peptide, protein, and site false discovery rates were set to 0.01. Label-free algorithm (Cox et al. 2011) was included, and the "match between runs" function was enabled.

Data were filtered and further analyzed using the in-house software tool Perseus. Intensity values were filtered for contaminant and reverse entries. The three experiments were split into subfiles, and each experiment was filtered for one valid value. Missing values of the LFQ intensities were imputed using a normal distribution at the lower-intensity range. Values are represented using the free software environment $\mathrm{R}$ (http://www.r-project.org).

A detailed list of peptide sequences obtained from MS analysis of the proteins is presented in Supplemental Table S1.

\section{Protein expression and purification}

Baculoviruses expressing Sfmbt, Scm, and Flag- $\mathrm{Ph}_{1298-1589}$ have been described previously (Klymenko et al. 2006; Grimm et al. 2009; Gambetta and Müller 2014). For this study, new viruses for Flag-Sfmbt ${ }_{530-1220}$ and Flag-Sfmbt ${ }_{530-1136}$ expression were generated after cloning the appropriate coding fragments into pFastBac. Flag affinity purification of protein (complexes) was performed as described (Grimm et al. 2009) with the following modifications: Instead of whole-cell extracts, cytosolic, nuclear, and chromatin extract were prepared in extraction buffer $(25 \mathrm{mM}$ HEPES at $\mathrm{pH} 7.9,150 \mathrm{mM} \mathrm{NaCl}, 20 \mu \mathrm{M} \mathrm{ZnCl}_{2}, 10 \%$ glycerol, $0.5 \mathrm{mM}$ DTT, $0.1 \%$ pefabloc-SC, $1 \times$ Complete protease inhibitor [Roche]) and subsequently combined to get the maximal amount of recombinant protein for purification. Insect cell extracts were precleared with mouse IgG-agarose beads (Sigma) for $45 \mathrm{~min}$ at $4^{\circ} \mathrm{C}$ on a rotating wheel prior to incubation with anti-Flag M2 agarose beads (Sigma) overnight at $4^{\circ} \mathrm{C}$. For $12 \mathrm{~mL}$ of extracts, $0.3 \mathrm{~mL}$ of anti-Flag beads was used.

For GST pull-down assays, GST-His-Sfmbt-SAM ${ }_{1137-1220}$, HisScm-SAM $_{803-877}$ L855E/L859E, and His-Ph-SAM 1499-1589 $_{\text {L1561E/L1565E }}$ were cloned into pET-derived vectors, individually expressed in Escherichia coli (Rosetta [DE], Novagen), and purified by nickel affinity purification. The purified GST-His-SfmbtSAM $_{1137-1220}$ domain was mixed with His-Scm-SAM ${ }_{803-877}^{\text {L855E/L859E }}$ or His-Ph-SAM $1499-15899^{\text {L1561E/L1565E }}$, coupled to glutathione beads for $2 \mathrm{~h}$ in binding buffer $(50 \mathrm{mM}$ phosphate buffer at $\mathrm{pH} 7.5,250 \mathrm{mM}$ 
$\mathrm{NaCl}, 10 \mathrm{mM} \mathrm{MgCl}_{2}, 10 \%$ glycerol, 0.01\% IGEPAL CA-630, $1 \mathrm{mM}$ pefablok-CS, $4 \mathrm{mM}$ dithiothreitol[DTT], $1 \times$ Complete protease inhibitor), and then washed three times with the same buffer but containing $200 \mathrm{mM}$ instead of $250 \mathrm{mM} \mathrm{NaCl}$. Beads were then resuspended in $150 \mu \mathrm{L}$ of $1 \times$ NuPAGE LDS sample buffer and incubated for $5 \mathrm{~min}$ at $95^{\circ} \mathrm{C}$ prior to SDS-PAGE. Binding assays with purified GST-His-GFP served as control.

The Sfmbt-SAM:Scm-SAM complex was obtained by cloning Sfmbt-SAM $1137-1220$ and Scm-SAM ${ }_{803-877}{ }^{\text {L855E/L859E }}$ into pET-derived vectors and coexpression in E. coli (Rosetta [DE], Novagen) as GST-His fusion and His fusion proteins, respectively. One liter of expression culture was resuspended in $25 \mathrm{~mL}$ of lysis buffer $(50$ mM phosphate buffer at $\mathrm{pH} 7.5,250 \mathrm{mM} \mathrm{NaCl}, 10 \mathrm{mM} \mathrm{MgCl}_{2}, 25$ $\mathrm{mM}$ immidazole, $10 \%$ glycerol, $0.1 \%$ Triton-X100, $1 \mathrm{mM}$ pefablok-CS, $2 \mathrm{mM} \beta$-mercaptoethanol, $1 \times$ Complete protease inhibitor), and cells were disrupted by sonication. SAM domains were purified by nickel affinity, GST affinity, ion exchange, and size exclusion chromatography. After the last purification step, samples were concentrated with Amicon Ultra centrifugal filters (3$\mathrm{kDa}$ cutoff; Millipore) to $7-15 \mathrm{mg} / \mathrm{mL}$.

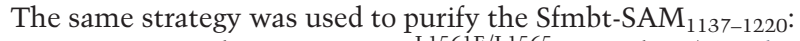
Scm-SAM ${ }_{803-869}-\mathrm{Ph}-\mathrm{SAM}_{1499-1577^{\text {L1561E/L1565 }}}$ complex (Supplemental Fig. S2C).

\section{Crystallization and $X$-ray structure determination}

All diffraction data were collected at the Swiss Light Source (SLS) synchrotron facility at beamline PXII. The data were processed with XDS (Kabsch 2010). All crystal structures were solved using Phaser from the PHENIX suite (Adams et al. 2010). The atomic models were built with Coot (Emsley et al. 2010) and refined using either the PHENIX suite (Adams et al. 2010) or the CCP4 suite (Winn et al. 2011). Validation was performed with MolProbity (Davis et al. 2007). Figures were made with PyMOL (version 1.2).

Crystals of the Sfmbt-SAM:Scm-SAM heterodimeric complex were grown at $4^{\circ} \mathrm{C}$ in $0.05 \mathrm{M}$ Tris $/ \mathrm{HCl}(\mathrm{pH} 7.5), 4 \% \mathrm{MPD}$, $0.2 \mathrm{M}$ ammonium acetate, and 32.5\% PEG3350. They contained two copies of the complex per asymmetric unit (space group P1 $2_{1}$ 1). A complete data set of an Sfmbt-SAM:Scm-SAM crystal, flashfrozen in liquid nitrogen, was collected to a resolution of $1.975 \AA$. The structure was solved by molecular replacement with the PhSAM:Scm-SAM heterodimer (PDB ID 1PK1) as a search model. Iterative model building and refinement were done with Coot and PHENIX-refine until the $\mathrm{R}$ factors converged. Interaction surfaces in the final structure were analyzed by visual inspection and by making use of the PDBePISA (proteins, interfaces, structures, and assemblies) service at the European Bioinformatics Institute (http://www.ebi.ac.uk/pdbe/prot_int/pstart.html; Krissinel and Henrick 2007).

Data collection and refinement statistics for the Drosophila Sfmbt-SAM:Scm-SAM complex structure are summarized in Supplemental Table S2.

\section{Drosophila strains, transgenes, and antibodies}

Drosophila strains generated for and used in this study are listed in Supplemental Table S3.

Transgenic lines expressing Flag-Scm and Flag-Scm ${ }^{\triangle S A M}$ under the control of a genomic promoter have been described (Peterson et al. 2004). For $S f m b t$ transgenes, a $10.5-\mathrm{kb}$ fragment comprising the Sfmbt promoter, coding, and 3' flanking regions (Berkeley Drosophila Genome Project R6 chr2L: 13,166,649-13,177,149| was cloned into a modified attB vector and integrated into the VK33 attP site. For the $S f m b t^{\Delta S A M}$ transgene, the TTG codon for Leu1133 in the same genomic fragment was mutated into TAG to create a premature termination codon.

The antibodies used are listed in Supplemental Table S4.

Total embryo extracts and small-scale embryo nuclear extracts

Embryos of the appropriate genotype were identified using GFPmarked balancer chromosomes. For total extracts, dechorionated embryos were briefly sonicated in $1 \times$ NuPage LDS sample buffer (Life Technologies) and heated for $5 \mathrm{~min}$ at $95^{\circ} \mathrm{C}$. After centrifugation at $16,000 \mathrm{~g}$ for $5 \mathrm{~min}$, the supernatant was directly analyzed by SDS-PAGE. Small-scale nuclear extracts were prepared using the subcellular fractionation kit for tissues (Thermo Scientific, no. 87790$)$.

Clonal analysis, immunostaining, and cuticle preparations of Drosophila

Immunostaining of embryos and imaginal discs and generation of clones in discs and adults were performed in animals of the appropriate genotypes using previously described protocols (Beuchle et al. 2001).

\section{ChIP analysis}

Chromatin preparation was performed as previously described (Gambetta et al. 2009) with the following modifications: Approximately 50 wing discs were sonicated for $30 \mathrm{~min}$ in $130 \mu \mathrm{L}$ of sonication buffer using Covaris S220 and the following settings: duty cycle: $2 \%$; peak incident power: $105 \mathrm{~W}$; cycles per burst: 200 . N-lauroylsarcosine was then added to a final concentration of $0.5 \%$ for $10 \mathrm{~min}$ at $4^{\circ} \mathrm{C}$, and debris was pelleted by centrifugation. The chromatin was dialyzed overnight and then used directly or stored at $-80^{\circ} \mathrm{C}$.

Primer sequences used for quantitative PCR analysis are listed in Supplemental Table S5 (Supplemental Table S5).

\section{Accession Numbers}

The accession number for the coordinates and structure factors reported in this study is PDB ID 5J8Y.

\section{Acknowledgments}

We thank the Max Planck Institute Crystallization Facility for crystal screening and optimization, and the beamline scientists at Swiss Light Source for excellent assistance with data collection. We are most grateful to Jeffrey Simon and Renato Paro for the generous gift of Drosophila strains and antibodies. This work was supported by the European Commission Seventh Framework Program 4DCellFate (grant no. 277899), the Deutsche Forschungsgemeinschaft (SFB1064) and the Max-Planck Society. F.F., C.B., and J.M. conceived the project, designed the experiments, discussed and interpreted the data, and prepared the manuscript. T.S. performed the ChIP analysis. K.F. provided technical support. G.S. and M.M. performed the mass spectrometric analysis.

\section{References}

Adams PD, Afonine PV, Bunkóczi G, Chen VB, Davis IW, Echols N, Headd JJ, Hung L-W, Kapral GJ, Grosse-Kunstleve RW, 
et al. 2010. PHENIX: a comprehensive Python-based system for macromolecular structure solution. Acta Crystallogr D Biol Crystallogr 66: 213-221.

Alfieri C, Gambetta MC, Matos R, Glatt S, Sehr P, Fraterman S, Wilm M, Müller J, Müller CW. 2013. Structural basis for targeting the chromatin repressor Sfmbt to Polycomb response elements. Genes Dev 27: 2367-2379.

Beuchle D, Struhl G, Müller J. 2001. Polycomb group proteins and heritable silencing of Drosophila Hox genes. Development 128: 993-1004.

Boettiger AN, Bintu B, Moffitt JR, Wang S, Beliveau BJ, Fudenberg G, Imakaev M, Mirny LA, Wu C-T, Zhuang X. 2016. Super-resolution imaging reveals distinct chromatin folding for different epigenetic states. Nature 529: 418-422.

Breen TR, Duncan IM. 1986. Maternal expression of genes that regulate the bithorax complex of Drosophila melanogaster. Dev Biol 118: 442-456.

Brown JL, Mucci D, Whiteley M, Dirksen ML, Kassis JA. 1998. The Drosophila Polycomb group gene pleiohomeotic encodes a DNA binding protein with homology to the transcription factor YY1. Mol Cell 1: 1057-1064.

Brown JL, Fritsch C, Mueller J, Kassis JA. 2003. The Drosophila pho-like gene encodes a YY1-related DNA binding protein that is redundant with pleiohomeotic in homeotic gene silencing. Development 130: 285-294.

Cao R, Wang L, Wang H, Xia L, Erdjument-Bromage H, Tempst $\mathrm{P}$, Jones RS, Zhang Y. 2002. Role of histone H3 lysine 27 methylation in Polycomb-group silencing. Science 298: 1039-1043.

Chan CS, Rastelli L, Pirrotta V. 1994. A Polycomb response element in the Ubx gene that determines an epigenetically inherited state of repression. EMBO J 13: 2553-2564.

Cheutin T, Cavalli G. 2012. Progressive polycomb assembly on H3K27me3 compartments generates polycomb bodies with developmentally regulated motion. PLOS Genet 8: e1002465.

Cox J, Mann M. 2008. MaxQuant enables high peptide identification rates, individualized p.p.b.-range mass accuracies and proteome-wide protein quantification. Nat Biotechnol 26: 1367-1372.

Cox J, Neuhauser N, Michalski A, Scheltema RA, Olsen JV, Mann M. 2011. Andromeda: a peptide search engine integrated into the MaxQuant environment. I Proteome Res 10: 1794-1805.

Czermin B, Melfi R, McCabe D, Seitz V, Imhof A, Pirrotta V. 2002. Drosophila enhancer of Zeste/ESC complexes have a histone H3 methyltransferase activity that marks chromosomal Polycomb sites. Cell 111: 185-196.

Davis IW, Leaver-Fay A, Chen VB, Block JN, Kapral GJ, Wang X, Murray LW, Arendall WB, Snoeyink J, Richardson JS, et al. 2007. MolProbity: all-atom contacts and structure validation for proteins and nucleic acids. Nucleic Acids Res 35: W375-W383.

Emsley P, Lohkamp B, Scott WG, Cowtan K. 2010. Features and development of Coot. Acta Crystallogr D Biol Crystallogr 66: 486-501.

Eskeland R, Leeb M, Grimes GR, Kress C, Boyle S, Sproul D, Gilbert N, Fan Y, Skoultchi AI, Wutz A, et al. 2010. Ring1B compacts chromatin structure and represses gene expression independent of histone ubiquitination. Mol Cell 38: 452-464.

Fischle W, Wang Y, Jacobs SA, Kim Y, Allis CD, Khorasanizadeh S. 2003. Molecular basis for the discrimination of repressive methyl-lysine marks in histone H3 by Polycomb and HP1 chromodomains. Genes Dev 17: 1870-1881.

Francis NJ, Saurin AJ, Shao Z, Kingston RE. 2001. Reconstitution of a functional core polycomb repressive complex. Mol Cell 8: $545-556$.
Francis NJ, Kingston RE, Woodcock CL. 2004. Chromatin compaction by a polycomb group protein complex. Science 306: 1574-1577.

Fritsch C, Brown JL, Kassis JA, Müller J. 1999. The DNA-binding polycomb group protein pleiohomeotic mediates silencing of a Drosophila homeotic gene. Development 126: 3905-3913.

Gambetta MC, Müller J. 2014. O-GlcNAcylation prevents aggregation of the Polycomb group repressor polyhomeotic. Dev Cell 31: 629-639.

Gambetta MC, Oktaba K, Müller J. 2009. Essential role of the glycosyltransferase sxc/Ogt in polycomb repression. Science 325: 93-96.

Gao Z, Zhang J, Bonasio R, Strino F, Sawai A, Parisi F, Kluger Y, Reinberg D. 2012. PCGF homologs, CBX proteins, and RYBP define functionally distinct PRC1 family complexes. Mol Cell 45: 344-356.

Girton JR, Jeon SH. 1994. Novel embryonic and adult homeotic phenotypes are produced by pleiohomeotic mutations in Drosophila. Dev Biol 161: 393-407.

Grau DJ, Chapman BA, Garlick JD, Borowsky M, Francis NJ, Kingston RE. 2011. Compaction of chromatin by diverse Polycomb group proteins requires localized regions of high charge. Genes Dev 25: 2210-2221.

Grimm C, de Ayala Alonso AG, Rybin V, Steuerwald U, Ly-Hartig N, Fischle W, Müller J, Müller CW. 2007. Structural and functional analyses of methyl-lysine binding by the malignant brain tumour repeat protein Sex comb on midleg. EMBO Rep 8: 1031-1037.

Grimm C, Matos R, Ly-Hartig N, Steuerwald U, Lindner D, Rybin V, Müller J, Müller CW. 2009. Molecular recognition of histone lysine methylation by the Polycomb group repressor dSfmbt. EMBO I 28: 1965-1977.

Guo Y, Nady N, Qi C, Allali-Hassani A, Zhu H, Pan P, AdamsCioaba MA, Amaya MF, Dong A, Vedadi M, et al. 2009. Methylation-state-specific recognition of histones by the MBT repeat protein L3MBTL2. Nucleic Acids Res 37: 2204-2210.

Houbaviy HB, Usheva A, Shenk T, Burley SK. 1996. Cocrystal structure of YY1 bound to the adeno-associated virus P5 initiator. Proc Natl Acad Sci 93: 13577-13582.

Illingworth RS, Moffat M, Mann AR, Read D, Hunter CJ, Pradeepa MM, Adams IR, Bickmore WA. 2015. The E3 ubiquitin ligase activity of RING1B is not essential for early mouse development. Genes Dev 29: 1897-1902.

Isono K, Endo TA, Ku M, Yamada D, Suzuki R, Sharif J, Ishikura T, Toyoda T, Bernstein BE, Koseki H. 2013. SAM domain polymerization links subnuclear clustering of PRC1 to gene silencing. Dev Cell 26: 565-577.

Jiao L, Liu X. 2015. Structural basis of histone H3K27 trimethylation by an active polycomb repressive complex 2. Science 350: aac4383.

Kabsch W. 2010. XDS. Acta Crystallogr D Biol Crystallogr 66: 125-132.

Kang H, McElroy KA, Jung YL, Alekseyenko AA, Zee BM, Park PJ, Kuroda MI. 2015. Sex comb on midleg (Scm) is a functional link between PcG-repressive complexes in Drosophila. Genes Dev 29: 1136-1150.

Kim CA, Gingery M, Pilpa RM, Bowie JU. 2002. The SAM domain of polyhomeotic forms a helical polymer. Nat Struct Biol 9: 453-457.

Kim CA, Sawaya MR, Cascio D, Kim W, Bowie JU. 2005. Structural organization of a Sex-comb-on-midleg/polyhomeotic copolymer. J Biol Chem 280: 27769-27775.

King IFG, Emmons RB, Francis NJ, Wild B, Müller J, Kingston RE, Wu C-T. 2005. Analysis of a polycomb group protein defines 
regions that link repressive activity on nucleosomal templates to in vivo function. Mol Cell Biol 25: 6578-6591.

Klose RJ, Cooper S, Farcas AM, Blackledge NP, Brockdorff N. 2013. Chromatin sampling-an emerging perspective on targeting polycomb repressor proteins. PLoS Genet 9: e1003717.

Klymenko T, Papp B, Fischle W, Köcher T, Schelder M, Fritsch C, Wild B, Wilm M, Müller J. 2006. A Polycomb group protein complex with sequence-specific DNA-binding and selective methyl-lysine-binding activities. Genes Dev 20: 1110-1122.

Krissinel E, Henrick K. 2007. Inference of macromolecular assemblies from crystalline state. J Mol Biol 372: 774-797.

Kuzmichev A, Nishioka K, Erdjument-Bromage H, Tempst P, Reinberg D. 2002. Histone methyltransferase activity associated with a human multiprotein complex containing the Enhancer of zeste protein. Genes Dev 16: 2893-2905.

Kwong C, Adryan B, Bell I, Meadows L, Russell S, Manak JR, White R. 2008. Stability and dynamics of polycomb target sites in Drosophila development. PLoS Genet 4: e1000178.

Levine SS, Weiss A, Erdjument-Bromage H, Shao Z, Tempst P, Kingston RE. 2002. The core of the polycomb repressive complex is compositionally and functionally conserved in flies and humans. Mol Cell Biol 22: 6070-6078.

Machida YJ, Machida Y, Vashisht AA, Wohlschlegel JA, Dutta A. 2009. The deubiquitinating enzyme BAP1 regulates cell growth via interaction with HCF-1. I Biol Chem 284: 34179-34188.

Margueron R, Justin N, Ohno K, Sharpe ML, Son J, Drury WJ, Voigt P, Martin SR, Taylor WR, De Marco V, et al. 2009. Role of the polycomb protein EED in the propagation of repressive histone marks. Nature 461: 762-767.

McKay DJ, Klusza S, Penke TJR, Meers MP, Curry KP, McDaniel SL, Malek PY, Cooper SW, Tatomer DC, Lieb JD, et al. 2015. Interrogating the function of metazoan histones using engineered gene clusters. Dev Cell 32: 373-386.

Min J, Zhang Y, Xu R-M. 2003. Structural basis for specific binding of Polycomb chromodomain to histone $\mathrm{H} 3$ methylated at Lys 27. Genes Dev 17: 1823-1828.

Mohd-Sarip A, Venturini F, Chalkley GE, Verrijzer CP. 2002. Pleiohomeotic can link polycomb to DNA and mediate transcriptional repression. Mol Cell Biol 22: 7473-7483.

Mohd-Sarip A, Cléard F, Mishra RK, Karch F, Verrijzer CP. 2005. Synergistic recognition of an epigenetic DNA element by Pleiohomeotic and a Polycomb core complex. Genes Dev 19: $1755-1760$.

Müller J, Hart CM, Francis NJ, Vargas ML, Sengupta A, Wild B, Miller EL, O'Connor MB, Kingston RE, Simon JA. 2002. Histone methyltransferase activity of a Drosophila Polycomb group repressor complex. Cell 111: 197-208.

Nekrasov M, Klymenko T, Fraterman S, Papp B, Oktaba K, Köcher T, Cohen A, Stunnenberg HG, Wilm M, Müller J. 2007. Pcl-PRC2 is needed to generate high levels of H3-K27 trimethylation at Polycomb target genes. EMBO J 26: 4078-4088.

Oktaba K, Gutiérrez L, Gagneur J, Girardot C, Sengupta AK, Furlong EEM, Müller J. 2008. Dynamic regulation by polycomb group protein complexes controls pattern formation and the cell cycle in Drosophila. Dev Cell 15: 877-889.

Pengelly AR, Copur Ö, Jäckle H, Herzig A, Müller J. 2013. A histone mutant reproduces the phenotype caused by loss of histone-modifying factor Polycomb. Science 339: 698-699.

Pengelly AR, Kalb R, Fink1 K, Müller J. 2015. Transcriptional repression by $\mathrm{PRC} 1$ in the absence of $\mathrm{H} 2 \mathrm{~A}$ monoubiquitylation. Genes Dev 29: 1487-1492.
Peterson AJ, Kyba M, Bornemann D, Morgan K, Brock HW, Simon J. 1997. A domain shared by the Polycomb group proteins Scm and ph mediates heterotypic and homotypic interactions. Mol Cell Biol 17: 6683-6692.

Peterson AJ, Mallin DR, Francis NJ, Ketel CS, Stamm J, Voeller RK, Kingston RE, Simon JA. 2004. Requirement for sex comb on midleg protein interactions in Drosophila polycomb group repression. Genetics 167: 1225-1239.

Rigaut G, Shevchenko A, Rutz B, Wilm M, Mann M, Séraphin B. 1999. A generic protein purification method for protein complex characterization and proteome exploration. Nat Biotechnol 17: 1030-1032.

Santiveri CM, Lechtenberg BC, Allen MD, Sathyamurthy A, Jaulent AM, Freund SMV, Bycroft M. 2008. The malignant brain tumor repeats of human SCML2 bind to peptides containing monomethylated lysine. J Mol Biol 382: 1107-1112.

Scheuermann JC, de Ayala Alonso AG, Oktaba K, Ly-Hartig N, McGinty RK, Fraterman S, Wilm M, Muir TW, Müller J. 2010. Histone H2A deubiquitinase activity of the Polycomb repressive complex PR-DUB. Nature 465: 243-247.

Schuettengruber B, Ganapathi M, Leblanc B, Portoso M, Jaschek R, Tolhuis B, van Lohuizen M, Tanay A, Cavalli G. 2009. Functional anatomy of polycomb and trithorax chromatin landscapes in Drosophila embryos. PLoS Biol 7: e13.

Shao Z, Raible F, Mollaaghababa R, Guyon JR, Wu CT, Bender W, Kingston RE. 1999. Stabilization of chromatin structure by PRC1, a Polycomb complex. Cell 98: 37-46.

Shevchenko A, Tomas H, Havlis J, Olsen JV, Mann M. 2006. Ingel digestion for mass spectrometric characterization of proteins and proteomes. Nat Protoc 1: 2856-2860.

Simon JA, Kingston RE. 2013. Occupying chromatin: Polycomb mechanisms for getting to genomic targets, stopping transcriptional traffic, and staying put. Mol Cell 49: 808-824.

Simon J, Chiang A, Bender W. 1992. Ten different Polycomb group genes are required for spatial control of the abdA and AbdB homeotic products. Development 114: 493-505.

Sowa ME, Bennett EJ, Gygi SP, Harper JW. 2009. Defining the human deubiquitinating enzyme interaction landscape. Cell 138: 389-403.

Stock JK, Giadrossi S, Casanova M, Brookes E, Vidal M, Koseki H, Brockdorff N, Fisher AG, Pombo A. 2007. Ring1-mediated ubiquitination of $\mathrm{H} 2 \mathrm{~A}$ restrains poised RNA polymerase II at bivalent genes in mouse ES cells. Nat Cell Biol 9: 14281435.

Strübbe G, Popp C, Schmidt A, Pauli A, Ringrose L, Beisel C, Paro R. 2011. Polycomb purification by in vivo biotinylation tagging reveals cohesin and Trithorax group proteins as interaction partners. Proc Natl Acad Sci 108: 5572-5577.

Tyanova S, Mann M, Cox J. 2014. MaxQuant for in-depth analysis of large SILAC datasets. Methods Mol Biol 1188: 351-364.

Wang $\mathrm{H}$, Wang L, Erdjument-Bromage H, Vidal M, Tempst $\mathrm{P}$, Jones RS, Zhang Y. 2004a. Role of histone H2A ubiquitination in Polycomb silencing. Nature 431: 873-878.

Wang L, Brown JL, Cao R, Zhang Y, Kassis JA, Jones RS. 2004b. Hierarchical recruitment of polycomb group silencing complexes. Mol Cell 14: 637-646.

Wang L, Jahren N, Miller EL, Ketel CS, Mallin DR, Simon JA. 2010. Comparative analysis of chromatin binding by Sex Comb on Midleg (SCM) and other polycomb group repressors at a Drosophila Hox gene. Mol Cell Biol 30: 2584-2593.

Wani AH, Boettiger AN, Schorderet P, Ergun A, Münger C, Sadreyev RI, Zhuang X, Kingston RE, Francis NJ. 2016. Chromatin topology is coupled to Polycomb group protein subnuclear organization. Nat Commun 7: 10291. 
Winn MD, Ballard CC, Cowtan KD, Dodson EJ, Emsley P, Evans PR, Keegan RM, Krissinel EB, Leslie AGW, McCoy A, et al. 2011. Overview of the CCP4 suite and current developments. Acta Crystallogr D Biol Crystallogr 67: 235-242.

Yu H, Mashtalir N, Daou S, Hammond-Martel I, Ross J, Sui G, Hart GW, Rauscher FJ, Drobetsky E, Milot E, et al. 2010. The ubiquitin carboxyl hydrolase BAP1 forms a ternary com- plex with YY1 and HCF-1 and is a critical regulator of gene expression. Mol Cell Biol 30: 5071-5085.

Zhang I, Bonasio R, Strino F, Kluger Y, Holloway JK, Modzelewski AJ, Cohen PE, Reinberg D. 2013. SFMBT1 functions with LSD1 to regulate expression of canonical histone genes and chromatin-related factors. Genes Dev 27: 749-766. 


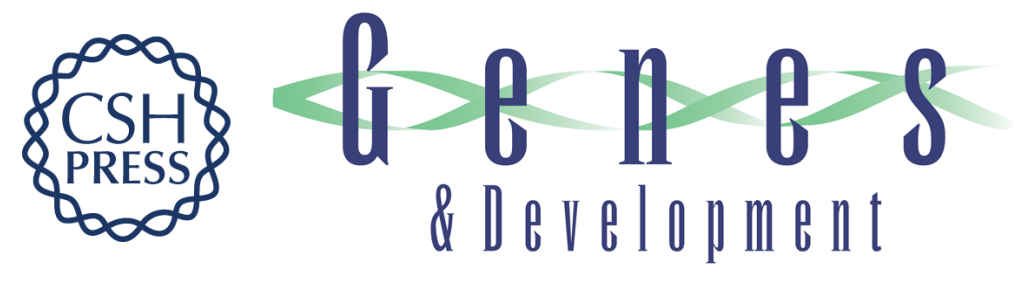

\section{Molecular basis of PRC1 targeting to Polycomb response elements by PhoRC}

Felice Frey, Thomas Sheahan, Katja Finkl, et al.

Genes Dev. 2016, 30:

Access the most recent version at doi:10.1101/gad.279141.116

\section{Supplemental http://genesdev.cshlp.org/content/suppl/2016/05/05/30.9.1116.DC1 Material}

References This article cites 75 articles, 34 of which can be accessed free at: http://genesdev.cshlp.org/content/30/9/1116.full.html\#ref-list-1

Creative This article is distributed exclusively by Cold Spring Harbor Laboratory Press for the first Commons six months after the full-issue publication date (see

License http://genesdev.cshlp.org/site/misc/terms.xhtml). After six months, it is available under a Creative Commons License (Attribution-NonCommercial 4.0 International), as described at http://creativecommons.org/licenses/by-nc/4.0/.

Email Alerting Receive free email alerts when new articles cite this article - sign up in the box at the top Service right corner of the article or click here.

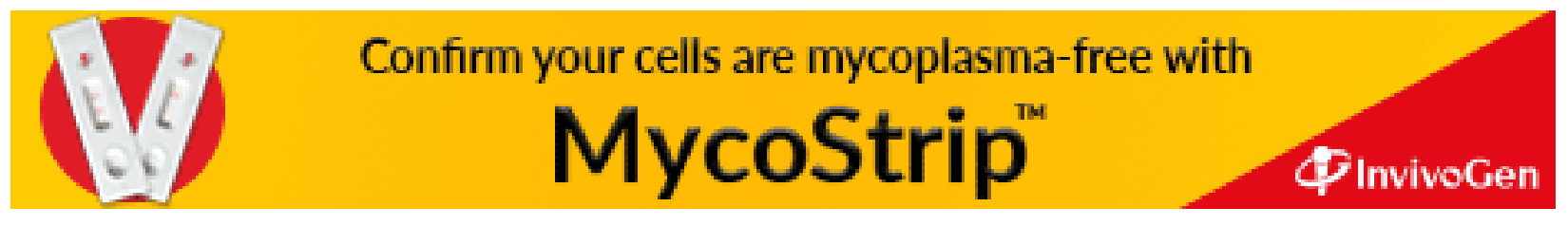

